Writing, Speaking and Communicating - Building Disciplinary Literacy in Materials Science Undergraduate Students.

Dr. Nancy Ruzycki, University of Florida

Director of Undergraduate Laboratories, Faculty Lecturer, Department of Materials Science and Engineering 


\title{
Writing, Speaking and Communicating - Building Disciplinary Literacy in Materials Science Undergraduate Students
}

\begin{abstract}
Disciplinary Literacy broadly defined involves students reading, speaking, and writing using habits of thinking that are practiced within a core discipline, and differs from content literacy in significant ways ${ }^{1-3}$. Disciplinary literacy is critical to education of engineers, owing to habits of thinking, and ways of communicating that uniquely comprise engineering practices. While there are many research based publications K12 on how disciplinary literacy enhances student learning outcomes, there is little research at the post-secondary level, and none to date related to engineering education. This preliminary study looks at (i) how disciplinary literacy practices can be used as tools to support core content ideas in engineering, build engineering habits of thinking, and effective communication and (ii) how students build towards effective disciplinary literacy practices when embedded in a collaborative class setting. A preliminary study was conducted within three undergraduate materials science courses in order to test these models; to investigate if embedded disciplinary literacy activities were successful in building effective student communication practices and content knowledge. A classroom conversation tool was employed $^{4}$, as well as student formative and summative assessments to judge student growth in disciplinary literacy, and content objectives.
\end{abstract}

\section{Keywords}

Disciplinary Literacy, Materials Science and Engineering, communication, undergraduate

\section{Introduction}

Early in the educational pathway students are taught skills of, and tools for reading text. Within the past twenty years reading experts diverged from a common method of reading instruction to publish work on content area literacy ${ }^{1-3,5}$. It has been recognized that each discipline has a specific language and way of writing that distinguishes it, and it has been proposed that teachers and instructors take notice of these best practices to specifically instruct students in how to read and apply content area literature ${ }^{5}$ in more than a novice way. Disciplinary literacy differs from content literacy in that it focus not on the mechanics of understanding content texts, but on knowledge and abilities utilized by those practicing within the discipline as experts. This includes creating, communicating and applying knowledge using the unique literacy tools and language of the discipline ${ }^{2}$.

The broader outcomes of disciplinary literacy practice are to build reflection and sense making in students, bringing them conceptually forward from their novice understanding. The link between sense making, and conceptual understanding has a research history in engineering ${ }^{6}$, and is explicitly linked for $\mathrm{K} 12$ science ${ }^{7,8}$. The purpose of infusing disciplinary literacy into engineering curriculum is to build habits of thinking, and to help students develop a deeper understanding of core content ideas. This aligns with development of expertise, as disciplinary literacy practices build towards effective communication using discipline specific content language ${ }^{9-15}$. The U.S. Accreditation Board for Engineering and Technology (ABET) holds engineering colleges accountable for knowledge, skills and professional values engineers acquire during the course of their education, and Effective Communication( student outcome $(\mathrm{g})$ ) is cross-cutting, yet there are few studies on how to build effective communication through disciplinary literacy practices in engineering ${ }^{16}$. 
This study looks at (i) how disciplinary literacy practices can be used as tools to support core content ideas in engineering, build engineering habits of thinking, and effective communication (ii) how students build towards effective disciplinary literacy practices when embedded in a collaborative class setting.

\section{Models for Disciplinary literacy practices as tools to support core content ideas in engineering, build engineering habits of thinking, and effective communication.}

Engineering literature is ripe with fruit from which to pluck research based learning strategies. Flipped classes, active learning via clickers, game based learning, and online classes can all be found on college campuses. What has not been presented in literature are simple research based learning strategies to support disciplinary literacy to build and support content knowledge, and engineering habits of mind. This paper will look at model practices that can be used to support disciplinary literacy through forms of "Structured or Accountable Talk".

One way to build knowledge is through use of structured talk in the classroom. This is sometimes labeled as "Accountable Talk" or "Structured Talk". "Accountable talk" has been defined" as talk that involves attention to, and builds on, the ideas of others, allows students to wrestle with ideas, where participants listen to, and learn from each other. In "Accountable Talk" students reach for discipline content to obtain facts, self-correct, and provide evidence for their explanations. "Accountable Talk" is rigorous, and builds on logical connections and reasonable supported conclusions.

Within an engineering classroom the type of discussion that students will have depends heavily on instructor questioning strategies, the student's background in reasoning and metacognition, and their ability to access and use content knowledge of the discipline. In order for students to engage in higherlevel thinking and reasoning, instructors may need to explicitly guide and scaffold students in discourse interactions. College engineering instructors have little training in discourse practices with students, and so may default to not allowing student voice in class, having student voice only in the form of group problem solving, or to ask or answer questions.

Within the physics community, knowledge has been developed to support structured talk as a way of building and supporting physics content through a model building process ${ }^{10,12}$. Hestenes developed a basic student-centered instructional design that uses discourse to support knowledge acquisition through modeling cycles ${ }^{10,12}$. Modeling physics instructors are trained and prepared with an agenda for student progress in order to guide student inquiry and discussion towards understanding through "Socratic" questioning and remarks. During the modeling cycle, technical terms and representational tools are introduced by the instructor as needed to refine models, facilitate activities that use and develop the models, and to improve quality of student discourse ${ }^{12}$. By structuring the "talk" that students do, the instructor ensures that students are working towards learning objectives through conversations they have with each other. The instructor is taught to listen to the language and use of content vocabulary in student discourse to see if students are developing a "correct" model.

Engineering builds in disciplinary literacy within engineering habits of $\operatorname{mind}^{6,13-14,16}$, and as a professional practice within a Kolb Cycle as part of the process of experiential learning, where reflective observation activities and abstract conceptualization activities create sense making for concepts ${ }^{6}$. Kolb writes in part"; "they must be able to create concepts that integrate their observations into logically sound theories... and use these theories to make decisions and solve problems." Through disciplinary literacy practices, students make an explicit connection between the definition of the concept, and the application and practice of the concept. 
Within the K12 community, disciplinary literacy has been implemented as a best practice to support student knowledge acquisition $^{1-5}$. Like higher-education faculty, few K12 teachers are trained in discourse with students, and there is a need for training in how to create meaningful conversation opportunities for students. In 2013, Stanford University developed a massive open online course on constructive classroom conversations. Within this course, they introduced a Conversation Analysis Tool $(\mathrm{CAT})^{4}$ for use in analyzing student discourse. This tool provide a means to judge how students built knowledge through discourse using two dimensions; how turns build on previous turns to effectively build up a clear and complete idea, and how turns effectively focus on lesson's objectives and show depth or fostering of intended learning. By providing examples of student discourse to calibrate the use of this tool, instructors are able to utilize this tool in their classroom as a gauge for development of content knowledge.

\section{How students build towards effective disciplinary literacy practices when embedded in a collaborative class setting}

"Accountable Talk" practices were embedded into three different types of material science \& engineering classes at the University of Florida in 2013-2014. One of the classes was a large service class (Introduction to Materials Science and Engineering) for engineers with over one hundred sophomore to senior students enrolled from all engineering departments. The second class was a required tracking class for the department (Error Analysis and Experimental Optimization) with fifty sophomore students. The third class was a required laboratory class for juniors (Materials Laboratory $1 \& 2$ ) with forty-five students broken into sections of ten to twelve.

The "Accountable Talk" practices that will be discussed here include; "Think-Pair-Share", "Quick Writes"/"Exit Tickets", and "Structured Discourse/Circle of Truth". The verbal discourse of the students was taped with student permission using digital recorders, and analyzed using the Conversation Analysis Tool (CAT) ${ }^{4}$. Student groups were selected at random, and the recorder was moved to a new group every ten minutes. No student names or identifying information was kept or recorded when the conversations were transcribed. The recordings were erased after transcription. Written communication for "Quick Writes"/"Exit Tickets" was judged using a rubric for use of content vocabulary, development of ideas, and supporting statements. The "Circle of Truth" was utilized only in the laboratory course.

\section{Think-Pair-Share}

"Think-Pair-Share" is well known in K12 circles and is designed to differentiate instruction by providing students time and structure for thinking on a given topic. This allows students to first individually develop an idea, before sharing and refining the idea with a peer. This learning strategy promotes student engagement through whole class response, rather than the instructor posing a question that only one student answers. Think-Pair-Share allows all students to have a voice, and to share their thinking. Through discussion with a peer, a student may expose a misperception, which can be countered and corrected in a timely way.

In the engineering courses, "Think-Pair-Shares" were used routinely in class, generally 2-3 times per hour. The question posited to students had to do with "big ideas" for the unit, and were designed to consolidate student learning. Questions were conceptual in nature, and related to questions students would see on formative or summative assessments. Some examples of questions posed to students included "Turn to your partner after thinking, and take turns discussing the difference between standard deviation and uncertainty in a measurement", or "Turn to your partner after thinking and discuss why covalently bonded materials are generally less dense than ionically or metallically bonded materials". Students were given 30 seconds to one minute to think, and two minutes to discuss the question. A student pair was then 
chosen at random to summarize their discussion in one minute. After this, another student pair was chosen and asked to either summarize what the first pair stated, or to add to, or refute student's statements. If student's statements built towards understanding, class proceeded. If not, the instructor would use clarifying questions to bring students to a developed concept, or reteach the concept to clarify, and another question would be posed.

Student formal feedback from courses as part of instructor evaluation indicated a high level of satisfaction with the "Think-Pair-Share" and over $70 \%$ of student respondents in all courses indicated that this was an effective learning tool to develop their understanding in the course. Twenty-three percent of students stated that they wanted more inclusion of "Think-Pair-Shares" and more time to talk to each other. Formative and summative assessments indicated that two-thirds of students answered questions similar to those from "Think-Pair- Share" successfully during summative assessments.

\section{“Quick Writes" and "Exit Tickets"}

"Quick Writes" and "Exit Tickets" were employed in much the same way as "Think-Pair-Share". These activities served to provide formative feedback to the instructor for student understanding of material. "Quick Writes" also provided feedback to students for their level of written understanding. It was found that within the courses, students needed vocabulary scaffolding for their "Quick Writes" and "Exit Tickets" if it related to concept ideas. As an example, a quick write might be "Using the following terms... explain why... " or "Using the concept of cation/anion ratio, explain...., using terms....

"Quick Writes" are a good way for an instructor to gauge level of student readiness for summative level (exam) discussion questions. Writings were timed at five minutes, usually at the beginning of class to reinforce a main idea taught in a previous class, and were held about once a week. These writings were graded according to a rubric, and only students who attended class that day received points for the exercise. This rewarded students who attended class. The students received a possible score of 15 points from the writing exercise, 12 possible from rubric (Table 1), and three for being in class and participating. Students received a copy of the rubric with areas of concern circled, along with comments on their paper. It took 2-3 hours to grade 100 papers, and papers averaged about 4 paragraphs at most.

Table 1: "Quick Write Rubric".

\begin{tabular}{|l|l|l|l|}
\hline Category/pts & 3 & 2 & 1 \\
\hline $\begin{array}{l}\text { Focus on } \\
\text { Content }\end{array}$ & $\begin{array}{l}\text { Student understands "big } \\
\text { idea" of the question, and } \\
\text { stays focused on this main } \\
\text { idea. }\end{array}$ & $\begin{array}{l}\text { Student understands main } \\
\text { idea. Topic is not focused, or } \\
\text { student drifts from main idea. }\end{array}$ & $\begin{array}{l}\text { Student does not understand } \\
\text { main idea. Student is not } \\
\text { focused on developing the } \\
\text { main idea. }\end{array}$ \\
\hline $\begin{array}{l}\text { Support for } \\
\text { topic }\end{array}$ & $\begin{array}{l}\text { The big idea is supported } \\
\text { by text references, or } \\
\text { through examples, or } \\
\text { problem solving. }\end{array}$ & $\begin{array}{l}\text { The big idea has some } \\
\text { support, but it is not well } \\
\text { developed. There is a lack of } \\
\text { text or example references. }\end{array}$ & $\begin{array}{l}\text { Support for the main idea is } \\
\text { lacking, or student used } \\
\text { opinion to support the main } \\
\text { idea. }\end{array}$ \\
\hline $\begin{array}{l}\text { Word } \\
\text { Choice } \\
\text { vocab) }\end{array}$ & $\begin{array}{l}\text { There is correct use of } \\
\text { content vocabulary words, } \\
\text { and the words are natural } \\
\text { in the flow of the writing. }\end{array}$ & $\begin{array}{l}\text { There is incorrect use of } \\
\text { content vocabulary, or it is } \\
\text { used with context to the main } \\
\text { idea. }\end{array}$ & $\begin{array}{l}\text { Student has not used } \\
\text { content vocabulary, or } \\
\text { expresses vocabulary at a } \\
\text { low level of understanding. }\end{array}$ \\
\hline Conventions & $\begin{array}{l}\text { Student has grammar, } \\
\text { usage, punctuation, } \\
\text { spelling at the level of a } \\
\text { college student. Writing } \\
\text { reads well. }\end{array}$ & $\begin{array}{l}\text { Student has some errors in } \\
\text { grammar, usage, punctuation, } \\
\text { or spelling. Writing is not } \\
\text { college level. }\end{array}$ & $\begin{array}{l}\text { Student has some errors in } \\
\text { grammar, usage, } \\
\text { punctuation, or spelling. } \\
\text { Writing is not college level. } \\
\text { Writing is disjointed. }\end{array}$ \\
\hline
\end{tabular}


Below are two transcribed responses to the "Quick Write" Prompt "What is the significance and difference between standard deviation(STD), standard deviation of the mean(SDOM), and uncertainty when applied to a set of measured values".

Written Response 1: "Standard deviation gives the average spread of the measured data points. This allows us to see the precision of our data. The lower the $\sigma_{x}$, the higher the precision. When the standard deviation of the mean is taken, we can see the average variance of data points from the mean. This can be related to the uncertainty as saying the SDOM is the uncertainty of an average value."

Written Response 2: "Standard deviation in measured values if the amount by which the measurements vary from the average/mean. It shows the accuracy of the measurements in relation to the average. SDOM shows the variation of the STD from the number of samples itself. It displays the reliability of the STD in a large or small number of samples. Uncertainty shows the reliability of the best guess (mean) and variation in the data."

In both written responses, students use a variety of terms and concepts learned within class. In the response, student one focuses on precision and student two on accuracy in regards to STD. Since STD is a measure of the spread of data from the mean, it is related to precision, and only somewhat to accuracy. Accuracy implies that an actual value is known, and the mean approaches this known value. In this case, the student focusing on accuracy is implying that the mean is the target value, which may or may not be true for a data set. Additionally, student two talks about reliability of STD, and reliability is related to a data set being reproducible, the student has not used the term correctly.

Using a grading rubric, students can be scored on their written response, and feedback can be given to them on use of disciplinary language in context. Students receive both written comments and the rubric back on "Quick Writes". These writing examples provide written feedback to students and the instructor for a written level of understanding for big ideas of the lecture or chapter. After writing exercises, the instructor can post exemplar "Quick Writes" in transcribed form and without identifying names to a class websites for students to view, with an explanation of why work was exemplary using the rubric.

"Exit Tickets" took two forms, and were purely formative. They could be a quick attempt at a problem solution, "So for problem 13.4, how would you approach a solution to the problem", or a "3-2-1" where students would list three things they learned today that they did not know before, two things that they may have struggled with, and one thing they had a question on. They could also be questioned in regards to attainment of learning objectives "Today's lesson had $\mathrm{N}$ objectives, which of these do you think was most successfully reached? Explain. Or, which was not attained? Why do you think it was not?" All students who turned in their forms received in-class points for turning in "Quick Writes". "Exit Tickets" were held 1-2 times per-week, and were much quicker to grade.

Student formal feedback found that students were less satisfied with "Quick Writes" and "Exit Tickets". Less than $30 \%$ of students felt these activities supported their understanding of material. Student comments included "feels like pop quizzes", "I want to leave class the last five minutes, not do an exit ticket", and "These made me feel like I didn't know the material". Greater than $50 \%$ of students in class were able to answer questions similar to quick write during summative assessments, with the percentage higher when the same question was used on an assessment.

\section{Structured Discourse and Circle of Truth}

"Structured Discourse" goes deeper than "Think-Pair-Share", and are structured conversations designed to have students connect core content "big ideas" to an application at hand. The purpose of structured 
discourse is to build knowledge by deeply listening, reflecting on what was said, and then building, clarifying or negotiating what was heard in order to build knowledge. There are three features of successfully implemented discourse, accountability to community, accountability to knowledge, and accountability to accepted standards of reasoning ${ }^{11}$. The success and level of student discourse is directly related to the level of knowledge that students have accessible within. When instructors start to use discourse in the classroom it is quickly evident that for students discussing content matter with an established body of knowledge is not a simple matter, and complex concepts do not immediately reveal themselves. When students provide incorrect, incomplete or wrong information to their peers, it creates a challenge that has to be resolved through a careful examination of core content.

Not every "Structured Discourse" was taped and transcribed, but discourse for a variety of collaborative activities was recorded, transcribed and analyzed using the Conversation Analysis Tool (CAT) ${ }^{4}$.

Table 2: Conversation Analysis Tool ${ }^{4}$.

\begin{tabular}{|l|l|l|l|l|}
\hline Dimension & 4 & 3 & 2 & 1 \\
\hline $\begin{array}{l}\text { Turns build on } \\
\text { previous turns to } \\
\text { build an idea }\end{array}$ & $\begin{array}{l}\text { Half or more of the } \\
\text { turns build on } \\
\text { previous turns to } \\
\text { effectively build } \\
\text { up a clear and } \\
\text { complete idea }\end{array}$ & $\begin{array}{l}\text { Half or more of the } \\
\text { turns build on } \\
\text { previous turns to } \\
\text { adequately build } \\
\text { up an idea, which } \\
\text { may be incomplete } \\
\text { or lack clarity. }\end{array}$ & $\begin{array}{l}\text { Few turns build on } \\
\text { previous turns to } \\
\text { build up an idea. }\end{array}$ & $\begin{array}{l}\text { Turns are not used } \\
\text { to build up an idea. }\end{array}$ \\
\hline $\begin{array}{l}\text { Turns focus on the } \\
\text { knowledge or } \\
\text { skills of the } \\
\text { lesson's objectives }\end{array}$ & $\begin{array}{l}\text { Half or more of the } \\
\text { turns effectively } \\
\text { focus on the } \\
\text { lesson's objectives } \\
\text { and show depth or } \\
\text { fostering of the } \\
\text { intended learning. }\end{array}$ & $\begin{array}{l}\text { turns or more of the } \\
\text { focus on the } \\
\text { lesson's } \\
\text { objectives, but this } \\
\text { focus may be } \\
\text { superficial or lack } \\
\text { clarity. }\end{array}$ & $\begin{array}{l}\text { Few turns focus on } \\
\text { the lesson's } \\
\text { objectives. }\end{array}$ & $\begin{array}{l}\text { Turns do not focus } \\
\text { on the lesson's } \\
\text { objectives. }\end{array}$ \\
\hline
\end{tabular}

"Structured Discourse" was not used in the large service class, but in smaller core content classes. These classes by curriculum design, had many embedded collaborative learning activities, and students struggled initially in understanding how to communicate with each other in order to build knowledge as a group. The conversation involved in "Structured Discourse" would last on average about ten minutes, involving three to four participants.

Below is an example of how this was used in a laboratory class where students were working to complete a dielectric materials challenge involving a written a research proposal based on their independent experimental ideas. The recorded conversation below was taped at one of the first group meetings. All participants had individual roles with describing rubrics within their group. The challenge was aligned with core content from courses students were concurrently enrolled in as a cohort.

The first time "Structured Discourse" was used in relation to a collaborative activity, it was not successful. Audio taping indicated that students were off topic in their conversations, or that they were "brain dumping" saying whatever was in their head, tangentially related to the topic.

This transcription starts about three minutes into this group's conversation. For two minutes, students are initially talking about the format of the proposal and some students are interrupting and talking over each other, at three minutes they begin to build a conversation. 
Speaker A: How many pellets do we want to make, because she said it was like uh five grams.

Speaker B: No, because we are not going to do just one pellet so we are definitely going to need controls and stuff

Speaker A: Yeah that's true

Speaker C: For the 0.6 it says about $1 \mathrm{~g}$ ?

Speaker D: How expensive were the dopants?

At six minutes

Speaker B : So should we plan to do like 3 pellets per thing so that we have uh error bars?

Speaker A: Yeah that would be good

Speaker D: Yeah I think 3 or five

Speaker B : Wait, point 3 or more

Speaker D, A, B: Yeah

Speaker A: So which, so which

Speaker D: interrupting - 9 pellets

Speaker A: 9 pellets?

Speaker A, C, B: Three, three three dopants (finally C takes over) so if we are doing three dopants are we only doing one concentration of each dopant?

Speaker B: Well yeah, that is the thing, do we want to explore like a gradient? from 1- 5 percent?

Speaker C (coming in over B): Do you want to?

Speaker B: continuing - or do you want to do $3 \%, 4 \%, 5 \%$, or go for the straight maximums we saw in the paper?

Speaker D: That's 45 pellets

Speaker A: No let's have a range

Using the CAT tool, one can say that less than half of the turns built on each other, and less than half are building on turns to build an idea of a research plan. The next week, prior to the next "Structured Discourse" section, the instructor and student Teaching Assistant(TA) modeled unsuccessful, and successful conversation. Students were given a copy of the CAT tool, and used it to judge modeled conversations. After this, students were asked to work in their groups to come to consensus on a draft experimental research plan. 
The third week, when student turned in their weekly progress reports, it was noticed that students were not using content vocabulary with a high level of expertise in their reports, and there was incorrect usage of key concept terms. In the following structured discourse, groups were given content vocabulary words related to their progress report, and their role was to discuss the word for five to seven minutes in context of their experiment and come to consensus on its meaning. Below is a transcript of a group conversation.

Students received the word sintering

Student A: We have the word sintering, and we have to come up with a good definition of sintering in context.

Student B: Sintering is the high temperature step for the processing of the ceramic

Student C: It brings the pellet together

Student A; It has to do more than bring it together, or it would be the same as pressing. How is this step different?

Student B: Well, in sintering you are doing the grain growth part.

Student A: I thought we did that in calcining?

Student C: No, calcining is the solid state reaction part that makes the material. It drives off all of the other reactants, and leaves us with our product, but it is all small grains or loose powder.

Student B: Yes, and then we press it to bring all the grains together, and then sintering grows those grains together.

Student A: So when we heat it to $1450{ }^{\circ} \mathrm{C}$, we are growing the grains. But I thought we wanted small grains?

Student C: Small, but not too small. 8 microns I think.

Student B: But if we didn't calcine right, we may sinter and not have gotten what we wanted since we sintered an incomplete reaction?

Student A: Yes I think so

Student C: Well we won't know until we do XRD if we have a pure phase or not. Let's agree on the definition of sintering in context.

Student A: Yes, well Ok what did we decide?

Student B: How about - Sintering occurs after pressing the small grains created by calcining the material together, so the grains can grow into a polycrystalline form. The purpose of sintering is to grow grains of a certain size and to densify the material.

Student C: This stage turns it into a hard dense ceramic. 
Student A: Yes this sounds right.

Using the CAT tool, one can see that in this conversation, almost all turns build on other turns to build up an idea for the word sintering. Students are using vocabulary in context to their experimental design, and that turns focus on the knowledge or skills of the lesson's objectives.

In formal feedback from students to instructor, no students mentioned the "Structured Discourse" in their comments. Students were required to write a daily summary of lab activities using disciplinary terms, and it was found that students had a higher incidence for using terms and building conceptual understanding for terms discussed during "Structured Discourse".

The "Circle of Truth" is based on modeling physics instructional discourse practices where students come together to discuss and compare their experimental data during model development using whiteboards. It is through these conversations using data as the central idea that students start to articulate a conceptual model, and find errors and flaws in their model building process ${ }^{10,12}$. When students enter the weekly lab, they grab a white board and start to display and chart the results of any data collected the previous week. Class then meets in a circle at the front of the lab, and each group has to discuss their data and what their results mean in context of larger objectives of the lab. Since laboratories are collaborative multi-week themed projects, student may be at different points in their experimental process from week to week.

There are rules for discourse and these are modeled for students by Teaching Assistant(TA) and Instructor. Peer students may ask only clarifying questions of the students and cannot make any other comments. Within the speaking group, each member must speak, and groups have three minutes to discuss their data without interruption. There is then three minutes of clarifying questions from peers. The goals for the discourse are to have students formulate, elaborate, analyze, evaluate and apply a conceptual content framework to their experimental process. It is here that students learn from each other, and ask clarifying questions that can help them better understand their own experimental data. The "Circle of Truth" takes twenty to thirty minutes of a three hour laboratory block. The "Circle of Truth" builds accountability within the laboratory for all stakeholders, and forces students to analyze their data prior to coming to laboratory in order to discourse with their peers. In this way it builds reflection, and communication practices through the act of clarifying and communicating within a group what to write and present, as well as the act of explaining and clarifying to peers what was found and analyzed as part of the experiment.

An illustrative example of this was during a multi-week lab where students proposed and conducted experiments to heat treat cold rolled cartridge brass. Students designed an experimental treatment for recovery, recrystallization or grain growth regimes, and collected data on hardness and grain size as a function of temperature or time. During the experimental design phase discourse within the circle, groups would gracefully challenge other groups using clarifying questions "So you say that you will heat treat to recrystallize at $350^{\circ} \mathrm{C}$, is this in the regime of $1 / 2$ to $1 / 3$ of the absolute melting point of brass?" By allowing for discourse around experiments and data, students learn to use vocabulary and content in context, build and refine knowledge, learn to clarify and negotiate with others.

Student formal feedback indicated students overwhelmingly (greater than 80\%) liked the "Circle of Truth" and looked forward to the discourse with their peer students. Comments included "I learned a lot from the "Circle of Truth" it helped me understand what to do to improve my data analysis. It made me accountable to be prepared for the lab each week".

\section{Summary}


Preliminary studies were conducted within three undergraduate materials science courses to see (i) how disciplinary literacy practices can be used as tools to support core content ideas in engineering, build engineering habits of thinking, and effective communication and (ii) how students build towards effective disciplinary literacy practices when embedded in a collaborative class setting. A classroom conversation tool was employed ${ }^{4}$, as well as student formative and summative assessments to judge student growth in disciplinary literacy, and content objectives.

Various forms of disciplinary literacy practices were implemented in three engineering courses including; "Accountable Talk" practices: "Think-Pair-Share", "Quick Writes"/"Exit Tickets" and "Structured Discourse/Circle of Truth". These practices supported core content idea development through enforced use of discipline specific terms in written and oral discourse by students.

Results indicate students were responsive to "Think-Pair-Share", with over $70 \%$ favorable student response. Additionally, during summative (exams) assessments, over $60 \%$ of students were able to answer questions correctly that were similar to those posited during these class exercises. Students were less satisfied with the "Quick Writes" and "Exit Tickets", with less than 30\% of students reporting these activities supported their understanding of material. In summative (exam) assessments greater than 50\% of the students in the class were able to answer questions similar to "Quick Writes". Students were uniformly positive about the "Circle of Truth", with $80 \%$ of students finding it helpful for their understanding of the material. The summative assessment for the "Circle of Truth" and "Structured Discourse" would be student lab notebooks, and student lab products including technical memos, reports and papers. Student language in the daily notebook summaries was analyzed for use of disciplinary language and concepts, and students had a higher incidence for use of terms and concepts discussed during these exercises.

Some practices are more difficult to implement than others, some required scaffolding by the instructor to successfully implement (Structured Discourse), and some practices were more popular with students than others (Think- Pair-Share, Circle of Truth). The implementation of these practices depends heavily on the comfort level and teaching style of the instructor, as well as the time an instructor has to develop and analyze the disciplinary literacy practices used within the course.

These preliminary studies indicate the promise in purposeful inclusion of disciplinary literacy practices with engineering classrooms to support core content ideas, and sketch out a few possible model practices and tools for use in classroom settings by instructors. These activities build sense making, reflective practice and engineering habits of mind within materials science courses, and show promise in helping students to move from a novice level of understanding towards expertise through the use of writing, speaking and communicating.

\section{References}

1. McConachie, S. M., \& Petrosky, A. R. (2009). Content matters: A disciplinary literacy approach to improving student learning. John Wiley \& Sons.

2. Shanahan, T., \& Shanahan, C. (2012). "What is disciplinary literacy and why does it matter?.", Topics in Language Disorders, 32(1), 7-18. 
3. Resnick, L. B., Michaels, S., \& O’Connor, C. (2010). "How (well-structured) talk builds the mind.”, 163-194. Preiss, D., \& Sternberg, R. J. (Eds). Innovations in educational psychology: perspectives on learning, teaching, and human development. Springer Publishers.

4. Hakuta K., Zwiers, J. , Rutherford-Quach, S. (2013). Constructive Classroom Conversations MOOC, Stanford University Courseware Materials.

5. Vacca, R. T., \& Vacca, J. A. L. (2005). Content Area Reading, $8^{\text {th }}$ Ed, Glenview, IL: Scott, Foresman.

6. Kolb, D. A. (2014). Experiential learning: Experience as the source of learning and development. FT Press.

7. Larry Yore, Gay L. Bisanz \& Brian M. Hand (2003) Examining the literacy component of science literacy: 25 years of language arts and science research, International Journal of Science Education, 25:6, 689-725, DOI: 10.1080/09500690305018.

8 Mercer*, N., Dawes, L., Wegerif, R., \& Sams, C. (2004). Reasoning as a scientist: ways of helping children to use language to learn science. British Educational Research Journal, 30(3), 359-377.

9. Atman, C. J., Kilgore, D., \& McKenna, A. (2008). "Characterizing design learning: A Mixed-Methods study of engineering designers' use of language". Journal of Engineering Education, 97(3), 309-326.

10. Redish, E. F., \& Smith, K. A. (2008). "Looking beyond content: Skill development for engineers". Journal of Engineering Education, 97(3), 295-307.

11. Sohmer, R., Michaels, S., O’Connor, M. C., \& Resnick, L. (2009). “Guided construction of knowledge in the classroom”., 105-130. Schwarz, B., Dreyfus, T. Hershkowitz, R., (EDs), Transformation of knowledge through classroom interaction, Routledge.

12. Hestenes, D. (1997). "Modeling methodology for physics teachers". In March AIP Conference Proceedings, 935-958. IOP Institute of Physics Publishing LTD.

13. Woods, D. R., Felder, R. M., Rugarcia, A., \& Stice, J. E. (2000). “The Future of Engineering education III. Developing critical skills". Change, 4, 48-52.

14. National Research Council.(2009). "Engineering in K-12 Education: Understanding the Status and Improving the Prospects". Washington, DC: The National Academies Press.

15. Michaels, S., O’Connor, C., \& Resnick, L. B. (2008). "Deliberative discourse idealized and realized: Accountable talk in the classroom and in civic life". Studies in philosophy and education, 27(4), 283-297.

16. Felder, R. M., \& Brent, R. (2003). Designing and teaching courses to satisfy the ABET engineering criteria. Journal of Engineering Education, 92(1), 7-25. 